\title{
Milestones of Clinical Oncology in the 20th Century
}

At the end of the 20th century we have to acknowledge that the problem of cancer remains substantially unsolved. Malignant diseases, as long as they are not cured, are still a scourge of mankind.

But oncology has had its successes over the last decades. In diverse areas of basic cancer research, etiology, pathogenesis, and epidemiology, the amount of detailed knowledge recently gathered exceeds that for many other disease entities. From a clinical point of view, numerous partial successes have been achieved; about half of all cancer patients can be cured permanently. Apart from certain hematologic, pediatric, and other malignancies such as seminoma, however, favorable prognoses can only be made for patients with relatively limited tumors. Only due to the recent availability of techniques that allow the identification of single tumor cells in various tissues and in the blood, have we learned that many malignancies are not truly localized, but rather are systemic diseases. This aspect of cancer biology might not have been enough taken into consideration, even though it has long been appreciated that cancer patients generally do not die of the primary tumor but rather of metastases. If for the coming century we plan to cure those tumors not treatable curatively today, we have to focus on effective and lasting elimination of early micrometastases.

Further we have to take into account the epidemiological data which leave no doubt that the worldwide overall cancer incidence is not decreasing. Although over the past decades single kinds of cancer receded, over the same period of time the occurrence of other forms of cancers increased. One important reason for the resulting constant overall increase in incidence for malignant disease is age: there is a clear-cut correlation between the observed increase in life expectancy in industrialized countries and reported cancer rates. In the future, a breakthrough concerning the cancer problem will therefore partly depend on our ability to decrease the agedependent incidence of malignancies. This is a very special challenge for clinical oncologists, who will as well be confronted with the task of further developing treatment strategies for elderly patients.

Recognizing new trends in research and development in oncology and reacting appropriately is one of the main tasks this journal's editorial board must fulfill. We believe that future therapeutic milestones in oncology can not be determined by researchers in a single clinical or experimental field. Rather, they will come from all areas involved in cancer research. Therefore, experts from all the major research fields that take part in the making of this journal have been asked to offer their own statements on oncology. These statements, to be published in the forthcoming editions of our journal (issue 23, 2000), will describe the state-of-the-art from each expert's point of view and provide perspectives on possible future developments. We especially recommend their reading.

Wolfgang Queißer, Mannheim Werner Scheithauer, Wien

\begin{tabular}{ll}
\hline KARGER & ( ) 2000 S. Karger GmbH, Freiburg \\
Fax +49 761 4520714 & Accessible online at: \\
$\begin{array}{l}\text { E-mail Information@Karger.de } \\
\text { www.karger.com }\end{array}$ & www.karger.com/journals/onk
\end{tabular}

